\title{
Membangun Jiwa Entrepreneurship
}

\author{
Fathurohmman, S.Th.I., M.Pd.I \\ Fathur5779@gmail.com \\ STID Al Biruni Cirebon
}

\begin{abstract}
The soul is not a physical part of a person's mind and personality include, synonymous with the spirit, mind, or the crew themselves. The use of the term is more often associated with life compared to the mundane spirit. Personality includes mental and physical attitude. According to Professor Edwood Chapman, mental attitude is a way of communicating or expressing a mood or character to others. If our expression to others positively, then we called the person a positive mental attitude. Conversely, if our expression to others negative, then we called the person a negative mental attitude. While enrteprenuer is one who is able to create a new business as well as creative and innovative to take the risk and uncertainty in order to achieve profit and growth by identifying opportunities and threats as well as combining with its available resources.

Entrepreneurship is the human soul owner who has a bit of foresight. He will always coexist interdependent with each other. Interdependent souls will bring glory to the appropriate disposition of individuals, human dignity has created for mutual interdependence, and able to take advantage of any of anything in the world.
\end{abstract}

Key Word: Build, enrteprenuer.

\section{Konsep Dasar Entrepreneurship}

Era pasar bebas memunculkan kompetisi ekonomi materialistik, tempattempat usaha kecil yang berada di perkampungan-perkampungan terus dijajah oleh kaum kapitalis yang bermata sipit atau berambut pirang, membuat masyarakat semakin terpuruk, masyarakat berusaha dengan berbagai cara untuk memenuhi kebutuhannya. terbatasnya lapangan pekerjaan juga meningkatkan jumlah pengangguran di Indonesia. Melihat kondisi tersebut, maka dunia pendidikan harus mampu berperan aktif menyiapkan sumber daya manusia terdidik yang mampu menghadapi berbagai tantangan kehidupan baik lokal, regional, nasional, maupun internasional. Ia tidak cukup hanya menguasai teori-teori, tetapi juga mau dan mampu menerapkannya dalam kehidupan sosial. Ia tidak hanya mampu menerapkan ilmu yang diperoleh di bangku sekolah atau kuliah, tetapi juga mampu memecahkan berbagai persoalan yang dihadapi dalam kehidupan seharihari.

Pendidikan yang dimaksud adalah pendidikan yang berorientasi pada pembentukan jiwa entrepreneurship, yaitu jiwa keberanian dan kemauan menghadapi problema hidup dan kehidupan secara wajar, jiwa kreatif untuk mencari solusi dan mengatasi problema tersebut, jiwa mandiri dan tidak bergantung pada orang lain. Pendidikan yang berwawasan kewirausahaan, adalah pendidikan yang menerapkan prinsip-prinsip dan 
metodologi ke arah pembentukan kecakapan hidup (life skill) pada peserta didiknya melalui kurikulum yang terintegrasi yang dikembangkan.

Berwirausaha harus melibatkan dua unsur pokok, yaitu peluang dan kemampuan menanggapi peluang, Berdasarkan hal tersebut maka definisi kewirausahaan adalah "tanggapan terhadap peluang usaha yang terungkap dalam seperangkat tindakan serta membuahkan hasil berupa organisasi usaha yang melembaga, produktif dan inovatif."

Dalam pandangan Islam, bekerja dan berusaha, termasuk berwirausaha boleh dikatakan bagian yang tak terpisahkan dari kehidupan manusia, keberadaannya sebagai khalifah fil-ardh dimaksudkan untuk memakmurkan bumi dan membawanya ke arah yang lebih baik. Kerangka pengembangan kewirausahaan di kalangan tenaga pendidik dirasakan sangat penting. Karena pendidik adalah agent of change yang diharapkan mampu menanamkan ciri-ciri, sifat, dan watak serta jiwa kewirausahaan atau jiwa entrepreneur bagi peserta didiknya. Disamping itu jiwa entrepreneur juga sangat diperlukan bagi seorang pendidik, karena melalui jiwa ini, para pendidik akan memiliki orientasi kerja yang lebih efisien, kreatif, inovatif, produktif serta mandiri.

Konsepsi Islam sangat jelas, jikan ingin berubah lebih maju harus mulai ditumbuhkan dari dirinya untuk berusaha dan giat bekerja sebagai bentuk realisasi dari kekhalifahan manusia, dalam Alquran disebutkan pada surat $A r-R a^{\prime} d$ : 11: yang artinya:
"Sesungguhnya Allah tidak akan merubah suatu kaum kecuali kaum itu mau merubah dirinya sendiri."

Maksud dari ayat tersebut yaitu masih bersifat $a$ 'am (umum) yakni siapa saja yang mencapai kemajuan dan kejayaan bila mereka sudah merubah sebab-sebab kemundurannya yang diawali dengan merumuskan konsepsi kebangkitan yang direncanakan.

\section{Entrepreuneur Sejati}

Sang entrepreneur sejati ialah Nabi Muhammad, beliau telah memulai merintis karir dagangnya ketika berumur 12 tahun dan memulai usahanya sendiri ketika berumur 17 tahun. Pekerjaan ini terus dilakukan sampai menjelang beliau menerima wahyu (beliau berusia sekitar 37 tahun). Dengan demikian beliau telah berprofesi sebagai entrepreneur selama 25 tahun ketika beliau menerima wahyu.

Nabi Muhammad Saw terlahir sebagai anak yatim. Ayahnya, Abdullah meninggal ketika Muhammad masih dalam kandungan ibunya. Muhammad kecil menjadi yatim piatu pada usia 6 tahun. Kemudian beliau diasuh oleh kakeknya Abdul Muthalib, setelah wafat, dilanjutkan pamannya Abu Thalib. Muhammad kecil harus membantu ekonomi keluarga dengan bekerja "serabutan" kepada penduduk Makkah. Pengalaman masa kecil itulah yang menjadi modal psikologis beliau di kemudian hari.

Pekerjaan menggembala ternak merupakan pekerjaan yang umum dilakukan oleh para Nabi dan Rasul, seperti Nabi Musa, Daud, dan Isa. Menurut catatan sejarah, di masa kecil 
Nabi Muhammad pernah menggembala ternak penduduk Makkah. Berikut Fungsi Leadership penggembala:

a. Pathfinding (mencari) padang gembalaan yang subur.

b. Directing (mengarahkan) menggiring ternak ke padang gembalaan.

c. Controlling (mengawasi) agar tidak tersesat atau terpisah dari kelompok.

d. Protecting (melindungi) dari hewan pemangsa dan pencuri.

e. Reflecting (perenungan) alam, manusia, dan ciptaan Allah.

\section{Karir Bisnis Nabi Muhammad}

Karir bisnis Nabi Muhammad dimulai ketika beliau masih berusia 12 tahun. Beliau ikut pamannya berdagang "ekspor-impor" ke Syam. Sejak itulah Nabi Muhammad melakukan semacam kerja magang (intership) yang berguna kelak ketika beliau mengelola bisnisnya sendiri.

Menjelang usia dewasa, beliau memutuskan perdagangan sebagai karirnya. Beliau menyadari bahwa pamannya bukanlah orang yang kaya namun memiliki beban keluarga yang cukup besar. Oleh karena itu, Muhammad muda berpikiran untuk ikut meringankan beban pamannya dengan berdagang.

Agaknya, profesi menjadi pedagang ini telah dimulai lebih awal daripada yang telah dikenal umum dengan modal dari Khadijah. Ketika merintis karirnya tersebut beliau memulai dengan berdagang kecil-kecilan di Kota Makkah. Beliau membeli barang-barang dari satu pasar kemudian menjualnya kepada orang lain.

Dalam melaksanakan bisnisnya tersebut beliau memperkaya diri dengan kejujuran, keteguhan memegang janji, dan sifat-sifat mulia lainnya sehingga penduduk Makkah mengenal Muhammad sebagai seorang yang terpercaya (Al Amin).

Para pemilik modal (investor) di Makkah waktu itu semakin banyak yang membuka peluang kemitraan dengan Muhammad. Salah seorang pemilik modal itu adalah Khadijah yang menawarkan kemitraan berdasarkan mudharabah (bagi hasil). Dalam hal ini Khadijah bertindak sebagai pemodal (shahibul mal), sementara Muhammad sebagai pengelola (mudharib).

Lebih kurang selama 28 tahun Nabi Muhammad menjalankan usaha dagang ke Yaman, Syria, Busra, Iraq, Yordania, dan kota-kota di perdagangan di jazirah Arab lainnya. Dengan demikian, di usia muda, Nabi Muhammad sudah menjadi pedagang internasional, karena wilayah perdagangannya meliputi hampir seluruh jazirah Arab.

\section{Bisnis setelah Menikah}

Setelah menikah, Nabi Muhammad semakin memperlebar sayap "kerajaan" bisnisnya. Namun sekarang beliau bertindak sebagai manajer sekaligus mitra dalam usaha istrinya. Untuk menjalankan bisnisnya, Nabi Muhammad melakukan perjalanan ke berbagai pusat perdagangan di seluruh penjuru negerinya dan negeri tetangga.

Perjalanan karir Nabi Muhammad sebagai seorang businessman dapat dirumuskan sebagai berikut.

Muhammad pada usia 12 tahun sudah diperkenalkan tentang bisnis oleh pamannya, Abu Thalib, dengan cara diikutsertakan dalam perjalanan bisnis 
ke Suriah atau diistilahkan dengan magang (intership).

Hal ini terus dilakukan sampai usia 17 tahun ketika beliau telah mulai membuka usaha sendiri. Dengan demikian pada usia ini beliau sudah menjadi "business manager". Pengalaman perdagangan (magang) yang diperoleh Muhammad dari pamannya, selama beberapa tahun menjadi modal dasar baginya disaat memutuskan menjadi pengusaha muda di Mekah. Beliau merintis usahanya dengan berdagang kecil-kecilan di sekitar Ka'bah.

Dengan modal pengalaman yang ada disertai kejujuran dalam menjalankan usaha bisnisnya, nama Muhammad mulai dikenal di kalangan pelaku bisnis (investor) di Mekah. Dalam kurun waktu yang tidak lama, Muhammad mulai menampakkan kelihaiannya dalam menjalankan usaha perdagangan. Bahkan beberapa investor Makkah tertarik untuk memercayakan modalnya untuk dikelola oleh Muhammad dengan prinsip bagi hasil (musyarakah-mudharabah) maupun penggajian. Pada tahapan ini Muhammad telah beralih dari business manager (mengelola usahanya sendiri) menjadi investment manager (mengelola modal investor).

Nabi Muhammad memiliki modal besar dan kesempatan untuk ekspansi bisnis sehingga mampu menjangkau pusat perdagangan yang ada di Jazirah Arab. Kejujuran beliau dalam berbisnis sehingga dikenal olah para pelaku bisnis sebagai Al-Amin menjadi daya tarik bagi kalangan investor besar untuk menginvestasikan modalnya kepada Muhammad, salah satu di antaranya adalah Khadijah yang di kemudian hari menjadi istri pertama beliau.

Dalam perkembangan selanjutnya, ketika pemilik modal Makkah mempercayakan pengelolaan perdagangan mereka kepada Muhammad muda, beliau menjadi "Investment Manager".

Di usia 25 tahun, usia yang masih relatif muda, Muhammad menikah dengan Khadijah, seorang pengusaha sukses Mekah. Secara otomatis Muhammad menjadi pemilik sekaligus pengelola dari kekayaan Khadijah. Penggabungan dua kekayaan melalui pernikahan tersebut tentunya semakin menambah usaha perdagangan mereka baik secara modal maupun penguasaan pangsa pasar. Pada tahapan ini Muhammad sudah menjadi business owner.

Setelah Muhammad menikah dengan Khadijah, beliau semakin gencar mengembangkan bisnisnya melalui ekspedisi bisnis secara rutin di pusatpusat perdagangan yang ada di jazirah Arab. Beliau intens mengunjungi pasarpasar regional maupun Internasional demi mempertahankan pelanggan dan mitra bisnisnya. Jaringan perdagangan beliau telah mencapai Yaman, Suriah, Busara, Iraq, Yordania, Bahrain, dan kota-kota perdagangan Arab lainnya.

Menjelang masa kenabian (berumur 38 tahun) di mana waktunya banyak dihabiskan untuk merenung, beliau telah sukses menjadi pedagang regional. Di mana wilayah perdagangannya meliputi Yaman, Suriah, Busra, Iraq, Yordania, Bahrain dan kota-kota perdagangan Jazirah Arab lainnya. Pada tahapan ini, beliau telah 
memasuki fase yang menurut Robert $\mathrm{T}$ Kiyosaki disebut financial freedom.

\section{Bisnis yang Luar Biasa}

Kehebatan berbisnis Muhammad bisa dilihat dalam sebuah riwayat yang menceritakan bahwa beliau pernah menerima utusan dari Bahrain. Muhammad menanyakan kepada AlAshajj berbagai hal dan orang-orang yang terkemuka serta kota-kota yang terkemuka di Bahrain. Pemimpin kabilah tersebut sangat terkejut atas luasnya pengetahuan geografis serta sentralsentral komersial Muhammad. Kemudian al-Ashajj berkata, "Sungguh Anda lebih mengetahui tentang negeri saya daripada saya sendiri dan Anda pula lebih banyak mengetahui pusatpusat bisnis kota saya dibanding apa yang saya ketahui." Muhammad menjawab, "Saya telah diberi kesempatan untuk menjelajahi negeri Anda dan saya telah melakukannya dengan baik." (Syafi'i Antonio, 2007).

Kunci sukses berdagang Nabi terletak pada sikap jujur dan adil dalam mengadakan hubungan dagang dengan para pelanggan. Itulah yang selalu dia tunjukkan ketika menjadi agen saudagar kaya Siti Khadijah ra, yang kemudian menjadi istri tercinta, untuk melakukan perdagangan ke Syiria, Jerussalem, Yaman, dan tempat-tempat lain. Dalam perjalanan perdagangan itu, Nabi mendapatkan perolehan keuntungan di luar dugaan. Nabi menandaskan kejujuran dan agar menjaga hubungan yang baik dan ramah kepada para pelanggan, maupun mitra dagang.

Prinsip Nabi, pedagang yang tak jujur, meskipun sesaat mendapatkan keuntungan banyak, pelan tapi pasti akan gagal dalam menggeluti profesinya. Karena itu, beliau selalu menasehati sahabat-sahabatnya untuk melakukan hal serupa. Apalagi saat Nabi memimpin umat di Madinah. Praktik-praktik perdagangan yang mengandung unsur penipuan, riba, judi, ketidakpastian, meragukan, eksploitasi, pengambilan untung yang berlebihan, dan pasar gelap beliau larang. Nabi juga memelopori standardisasi timbangan dan ukuran.

Nabi sangat memperhatikan kejujuran. Sampai-sampai, orang yang jujur dalam berdagang, digaransinya masuk dalam golongan para nabi. Abu Sa'id meriwayatkan bahwa Rasulullah berkata, "Saudagar yang jujur dan dapat dipercaya akan dimasukkan dalam golongan para nabi, orang-orang jujur dan para syuhada."

\section{Sikap Baik dalam Berdagang}

Dalam urusan dagang, nabi selalu bersikap sopan dan baik hati. Jabir meriwayatkan bahwa Rasulullah berkata, "Rahmat Allah atas orang-orang yang berbaik hati ketika ia menjual dan membeli, dan ketika dia membuat keputusan." (HR Bukhari). Nabi juga menghindari sikap belebihan dalam berdagang, seperti banyak bersumpah. Tentang hal ini, nasehat Rasulullah, "Hindarilah banyak bersumpah ketika melakukan transaksi dagang, sebab itu dapat menghasilkan penjualan yang cepat, lalu menghapuskan berkah."

Nabi sangat membenci orangorang yang dalam dagangnya menggunakan sumpah palsu. Beliau mengatakan, pada hari kiamat nanti, Allah tidak akan berbicara, melihat pun tidak kepada orang yang semasa hidup 
berdagang dengan menggunakan sumpah palsu.

\section{Hak-Hak Kelompok dalam Transaksi}

Dalam proses pertukaran barang dengan persetujuan antara kedua belah pihak, seringkali ada konflik. Untuk menghindari ini, Nabi telah meletakkan dasar, bagaimana transaksi seharusnya terjadi. Ibnu 'Umar meriwayatkan dari Rasulullah, "Kedua kelompok di dalam transaksi perdagangan memiliki hak untuk membatalkannya hanya sejauh mereka belum berpisah, kecuali transasksi itu menyulitkan kelompok itu untuk membatalkannya." (HR Bukhari dan Muslim)

Dalam riwayat lain disebutkan, "Kedua belah pihak dalam transaksi perdagangan berhak membatalkan, selama mereka tidak berpisah. Jika mereka berkata benar, menjelaskan sesuatunya dengan jernih, maka transaksi mereka akan mendapatkan berkah. Tapi jika menyembunyikan sesuatu serta berdusta, maka berkah yang ada dalam transaksi mereka akan terhapus." (Bukhari dan Muslim).

Bila berpegang pada sekelumit teladan Nabi itu, mestinya umat Islam sudah menjadi bagian terdepan dalam penguasaan ekonomi dunia. Tapi sayangnya, banyak ajaran Nabi dalam berdagang yang dilupakan. Kalau ingin perdagangan umat Islam semaju Singapura, mestinya prinsip-prinsip dagang Rasul tidak dijadikan kenangan, tapi pegangan.

\section{Metode Praktis Berdagang Nabi}

1. Penjual tidak boleh berbohong dan menipu barang yang akan dijual kepada pembeli. Nabi bersabda,
"Apabila dilakukan penjualan, katakanlah: tidak ada penipuan."

2. Kepada para pelanggan yang tak mampu membayar kontan hendaknya diberikan waktu untuk melunasinya. Bila betul-betul dia tidak mampu membayar setelah masa tenggat pengunduran itu, Nabi akan mengikhlaskannya.

3. Penjual harus menjauhi sumpah yang berlebih-lebihan, apalagi sumpah palsu untuk mengelabui konsumen.

4. Hanya dengan kesepakatan bersama, atau dengan suatu usulan dan penerimaan antara kedua belah pihak, suatu bentuk transaksi barang akan sempurna.

5. Penjual harus benar dalam timbangan dan takaran.

6. Orang yang benar-benar membayar di muka untuk pembelian suatu barang, tidak boleh menjualnya sebelum barang tersebut benar-benar menjadi miliknya.

7. Larangan melakukan transaksi monopoli dalam perdagangan. "Barang siapa yang melakukan monopoli, maka dia adalah pendosa."

8. Tidak ada harga komoditi yang boleh dibatasi. Jika harga dibatasi, lalu tidak ada perusahaan dagang dan niaga, maka perdagangan dunia akan terhenti.

"Hai orang-orang yang beriman, janganlah kamu saling memakan harta sesamamu dengan jalan bathil, kecuali dengan jalan perniagaan yang berlaku dengan suka sama suka di antara kamu." (QS. An-Nisa:29)

Rasulullah SAW telah menentukan indikator jual beli yang mabrur dalam sebuah hadits sebagai berikut, "Jika penjual dan pembeli itu jujur dan 
transparan, maka akan diberkahi dalam transaksinya." (HR. Bukhari no. 2079 dan Muslim no. 1532)

Pemahaman yang utuh tentang biografi kehidupan beliau akan menghindarkan terjadinya pemahaman yang sempit tentang diri Rasulullah. Banyak orang yang menganggap Rasulullah sebagai orang yang miskin, padahal justru sebaliknya beliau adalah sosok pebisnis yang sukses.

\section{Integritas Pendidikan Entrepreneurship}

Keberhasilan seorang entrepreneur dalam Islam bersifat independen. Artinya keunggulannya berpusat pada integritas pribadinya, bukan dari luar dirinya. Hal ini selain menimbulkan kehandalan menghadapi tantangan, juga merupakan garansi tidak terjebak dalam praktek-praktek negatif dan bertentangan dengan peraturan, baik peraturan agama maupun peraturan teknis negara tentang usaha. Integritas entrepreneur muslim tersebut terlihat dalam sifat-sifatnya, antara lain:

- Takwa, tawakal, zikir, dan bersyukur.

Seorang entrepreneur muslim memiliki keyakinan yang kukuh terhadap kebenaran agamanya sebagai jalan keselamatan, dan bahwa dengan agamanya ia akan menjadi unggul. Keyakinan ini membuatnya melakukan usaha dan kerja sebagai dzikir dan bertawakal serta bersyukur pasca usahanya.

- Motivasinya bersifat vertikal dan horisontal.

Secara horizontal terlihat pada dorongannya untuk mengembangkan potensi dirinya dan keinginannya untuk selalu mencari manfaat sebesar mungkin bagi orang lain. Sementara secara vertikal dimaksudkan untuk mengabdikan diri kepada Allah Swt. Motivasi di sini berfungsi sebagai pendorong, penentu arah dan penetapan skala prioritas.

- Niat Suci dan Ibadah

Bagi seorang muslim, menjalankan usaha merupakan aktifitas ibadah sehingga ia harus dimulai dengan niat yang suci (lillahi ta'ala), cara yang benar, dan tujuan serta pemanfaatan hasil secara benar. Sebab dengan itulah ia memperoleh garansi keberhasilan dari Tuhan.

- Azam "Bangun Lebih Pagi"

Rasulullah mengajarkan kepada kita agar mulai bekerja sejak pagi hari. Setelah salat Subuh, kalau tidak terpaksa, sebaiknya jangan tidur lagi. Bergeraklah untuk mencari rezeki dari Rab-mu. Para malaikat akan turun dan membagi rezeki sejak terbit fajar sampai terbenam matahari.

- Selalu berusaha Meningkatkan llmu dan Keterampilan

Ilmu pengetahuan dan ketrampilan, dua pilar bagi pelaksanaan suatu usaha. Oleh karenanya, memenej usaha berdasarkan ilmu dan ketrampilan di atas landasan iman dan ketaqwaan merupakan salah satu kunci keberhasilan seorang entrepreneur.

- Jujur

Kejujuran merupakan salah satu kata kunci dalam kesuksesan seorang entrepreneur. Sebab suatu usaha tidak akan bisa berkembang sendiri tanpa ada kaitan dengan orang lain. Sementara kesuksesan dan kelanggengan hubungan dengan orang lain atau pihak lain, sangat 
ditentukan oleh kejujuran keduabelah pihak.

- Suka Menyambung Tali Silaturahmi

Seorang entrepreneur haruslah sering melakukan silaturahmi dengan mitra bisnis dan bahkan juga dengan konsumennya. Hal ini harus merupakan bagian dari integritas seorang entrepreneur muslim. Sebab dalam perfektif Islam, silaturahmi selain meningkatkan ikatan persaudaraan juga akan membuka peluang - peluang bisnis baru.

- Menunaikan Zakat, Infaq, dan Sadaqah (ZIS)

Menunaikan zakat, infaq, dan sadaqah harus menjadi budaya entrepreneur muslim. Menurut Islam sudah jelas, harta yang digunakan untuk membayar ZIS, tidak akan hilang, bahkan menjadi tabungan kita yang akan dilpatgandakan oleh Allah, di dunia dan di akhirat kelak.

- Puasa, Salat Sunat dan Salat Malam

Hubungan antara bisnis dan keluarga ibarat dua sisi mata uang sehingga satu sama lain tidak bisa dipisahkan. Sebagai seorang entrepreneur, disamping menjadi pemimpin di perusahaannnya dia juga menjadi pemimpin di rumah tangganya. Membiasakan keluarga, istri, anak, untuk melaksanakan puasa-puasa atau salatsalat sunat dan salat malam harus dilakukan seorang entrepreneur muslim, karena dapat memberikan bekal rohani untuk menjalankan usahanya.

- Mengasuh Anak Yatim

Sebagai entrepreneur, mengasuh anak yatim merupakan kewajiban. Mengasuh atau memelihara dalam arti memberikan kasih sayang dan nafkah (makan, sandang, papan dan biaya pendidikan). Lebih baik lagi bila juga kita berikan bekal (ilmu atau agama/ atau keterampilan) sehingga mereka akan mampu mandiri menjalani kehidupan di kemudian hari.

Sebagai konsekuensi pentingnya kegiatan entrepreneurship, Islam menekankan pentingnya pembangunan dan penegakkan budaya entrepreneurship dalam kehidupan setiap muslim. Budaya entrepreneurship muslim itu bersifat manusiawi dan religius, berbeda dengan budaya profesi lainnya yang tidak menjadikan pertimbangan agama sebagai landasan kerjanya. Dengan demikian pendidikan entrepreneur muslim akan memiliki sifat - sifat dasar yang mendorongnya untuk menjadi pribadi yang kreatif dan handal dalam menjalankan usahanya atau menjalankan aktivitas pada perusahaan tempatnya bekerja.

Jiwa entrepreneur seseorang bukanlah merupakan faktor keturunan, namun dapat dipelajari secara ilmiah dan ditumbuhkan bagi siapapun juga. Pendidikan entrepreneurship dapat dilakukan apabila pendidik sudah memiliki jiwa entrepreneur yang tinggi. Yang penting dan yang utama dari pendidikan entrepreneurship adalah semangat untuk terus mencoba dan belajar dari pengalaman. "Gagal itu biasa, berusaha terus itu yang luar biasa", mungkin seperti itulah gambaran yang harus dikembangkan oleh manusiamanusia Indonesia agar tetap eksis dalam pertarungan bisnis yang semakin transparan dan terbuka. 


\section{REFERENSI:}

Afzallurahman dalam Muhammad SAW (a Trader).

Al-Qur'an dan hadist HR. Bukhori Muslim.

Bisnis Ekonomi Syariah.

DR Muhammad Syafi'i Antonio M.Ec Muhammad SAW, Super Leader Super Manager.

http://pendidikanentrepreneurshipdal amperspektifislam.rifqiemaulan a.wordpress.com

http://wirausahanet.tripod.com/id10.h $\underline{\mathrm{tml}}$

M. Ismail Yusanto dan M. Karebet Wijayakusuma. Menggagas Bisnis Islami.

Muhammad SAW SupIer Leader Super Manager, Dr. Syafi'i Antonio.

Siroh Nabawiyah.

www. 1.bp.blogspot.com

www.hidayatullah.com

www.rkypd.wordpress.com

Ya'qub. Kode Etik Dagang Menurut Islam. 